\title{
Micromole per Mole
}

National Cancer Institute

\section{Source}

National Cancer Institute. Micromole per Mole. NCI Thesaurus. Code C122231.

A unit of fraction expressed as the ratio of the amount of a substance in solution, in micromoles, to the amount of a different substance in the mixture, in moles. 